\title{
O TRIBUNAL ESPECIAL PARA O LÍBANO: UM BALANÇO PARCIAL (2009-2019)
}

THE SPECIAL TRIBUNAL FOR LEBANON: A PARTIAL ASSESSMENT (2009-2019)

Luiz Augusto Módolo de Paula*

\begin{abstract}
Resumo:
O presente artigo faz um balanço parcial das atividades do Tribunal Especial para o Líbano - TEL, tribunal penal internacional ad hoc, abrangendo os anos de 2009 a 2019, e analisa sua proposta de punição de atos de terrorismo e sua viabilidade como modelo para a repressão deste grave crime pela sociedade internacional.

Palavras-chave: Direito Internacional Penal. Direito Internacional Público. Líbano. Tribunal Especial para o Líbano.
\end{abstract}

\begin{abstract}
:
This paper makes a partial assessment of the activities of the Special Tribunal for Lebanon, an ad hoc international criminal court, covering the years of 2009 through 2019 , and analyses its proposal of punishment of terrorist acts and its viability as a model to the repression of terrorism by the international society.
\end{abstract}

Keywords: International Criminal Law. Public International Law. Lebanon. Special Tribunal for Lebanon.

Introdução

O intento deste artigo é fazer um balanço parcial das atividades do Tribunal Especial para o Líbano - TEL, abrangendo os anos de 2009 a 2019.

O TEL é um tribunal penal internacional ad hoc, uma corte oriunda de um acordo entre a Organização das Nações Unidas (ONU) e o Estado do Líbano, que nos anos de 2004 e 2005 foi sacudido por uma série de atentados terroristas graves, especialmente destacando-se o atentado a bomba que vitimou Rafik Hariri, ex-primeiro-ministro do Líbano, em 14 de fevereiro de 2005.

O principal diferencial do TEL em relação a outros tribunais penais internacionais ad hoc é que ele é uma corte que visa julgar atos de terrorismo com base na legislação doméstica de um Estado (no caso, o Líbano), e não crimes de genocídio, crimes de guerra e crimes contra a humanidade, que têm tipificação oriunda de tratados

Doutor (2016) e mestre (2011) em Direito Internacional e bacharel em Direito (2001) pela Universidade de São Paulo. Procurador do Município de São Paulo. E-mail: luaump@yahoo.com.br. O autor dedica este artigo ao seu tio, Luiz Ovídio Módolo, que trabalhava num kibutz no norte de Israel em 1982 e acompanhou de perto o conflito no Líbano. 
internacionais, como é o caso dos Tribunais Penais Internacionais para a ex-Iugoslávia e para Ruanda.

1. Líbano: um breve recorte geográfico e histórico

Apresentemos brevemente o Líbano, o País dos Cedros, com um breve resumo de alguns fatos históricos que culminaram com os atentados terroristas dos anos 2000 e a criação do TEL.

O Líbano é um Estado litorâneo situado no Oriente Médio, na extrema margem direita do Mar Mediterrâneo, com um território de $10.452 \mathrm{~km}^{2}$ e população de 6,075 milhões de habitantes, aproximadamente, em fevereiro de 2019 (WORLDOMETERS, 2019).

O país abriga dezenove comunidades religiosas principais, contando com cristãos maronitas, ortodoxos gregos e armênios, muçulmanos xiitas, sunitas, drusos e palestinos refugiados. ${ }^{1}$

O Líbano tem como língua oficial o árabe, com pequenas diferenças entre o "árabe falado" (dialeto libanês) e o "árabe escrito" (comum a todos os países árabes). Francês e inglês são bastante falados no país, até por questões da ocupação ocidental ocorrida na primeira metade do século XX.

O país por muito tempo foi parte do Império Otomano, que acabou após a Primeira Guerra Mundial. A região, junto com a Síria, passou a ser parte de um mandato francês, dentro do bojo da celebração do conhecido tratado Sykes-Picot (FrançaInglaterra). ${ }^{2}$

Segundo lição de Renata Mantovani de Lima (2012, p. 171-172), o Líbano se tornou independente em 1943 (com encerramento do mandato francês em 1941), abrigando uma população multiétnica e grosso modo dividida em três territórios. A região

1 Sobre os palestinos, nos ensina Fernanda Resende Djahjah (2013, p. 21): "Com a criação do Estado de Israel em 1948, e posteriormente, em 1967, com a Guerra dos Seis Dias entre árabes e o Estado Judeu, em que os árabes perderam, muitos refugiados palestinos chegaram ao Líbano. A partir disso, começaram os problemas decorrentes da atuação da OLP (Organização para a Libertação da Palestina) no Sul do país e sua atuação violenta perante Israel. Como não havia um consenso em relação a que política adotar diante da OLP, seu poder no Sul foi sendo ampliado. Todo esse contexto gerou uma instabilidade política a partir do ano de 1969 e a questão palestina teve que ser enfrentada pelo governo libanês. Pressionado, o governo aceitou discutir a permanência palestina no Líbano, que resultou no Acordo de Cairo, extremamente prejudicial à soberania libanesa, já que a OLP se tornou praticamente um 'Estado dentro do Estado'. A entrada de palestinos, além de ter gerado um problema de soberania para o Líbano, resultou também em um aumento no número de muçulmanos no Estado libanês".

2 A França tinha pretensões na região norte dos territórios árabes e ficou como tutora do Líbano e da Síria, enquanto os ingleses mantinham seus interesses nas regiões sul - do Egito ao Iraque (BUNTON, 2013, p. 446). O texto integral do tratado pode ser lido em Wiliander Salomão (2017, p. 49-51). 
do Monte Líbano, ao norte, abrigava a população cristã maronita. Os muçulmanos sunitas e xiitas ocupavam diversas áreas no interior e no litoral do país.

Mas basicamente o Líbano era um país de maioria cristã, cercado de países árabes muçulmanos e abrigando uma população muçulmana que sequer podia ser chamada de minoria.

O poder passou a ser dividido entre as diversas etnias e religiões, num arranjo frágil, chamado informalmente de Pacto, com preponderância de ocupação de postos de governos pelos cristãos e pelos muçulmanos sunitas. ${ }^{3}$

Mas dentro das próprias etnias havia diferenças. Muitos drusos pertenciam também ao clã Arslan ou Jumblatt. E dentre os cristãos maronitas os clãs mais fortes eram os Gemayel e Franjieh.

Em 1958 eclodia uma guerra civil. Em meados da década de 1970 outra guerra civil, ainda pior, começava.

Em 13 de abril de 1975, pistoleiros tentaram assassinar Pierre Gemayel, matando quatro de seus correligionários. Gemayel era fundador da Falange, uma organização paramilitar maronita inspirada no fascismo (fundação em 1936), e este ataque desencadeou a guerra civil, sendo chamada por Thomas Colello de "a Sarajevo da guerra civil de $1975 " .4$

Os combates aconteciam principalmente em áreas urbanas e, ao longo dos anos de duração da guerra, grandes partes da então magnífica Beirute foram transformadas em escombros. ${ }^{5}$

Os dois principais lados em guerra eram cristãos (Fronte Libanês), pela manutenção do status quo, com proeminência da Falange na liderança (e no grosso da composição das tropas combatentes), e muçulmanos (Movimento Nacional Libanês), liderados pelo druso Kamal Jumblatt, por sua vez apoiados por parcelas da Organização para a Libertação da Palestina - OLP e diversas outras milícias (COLLELO, 1989, p. 30). ${ }^{6}$

3 Segundo Robert Fisk (2007, p. 111) os maronitas concordaram com um Pacto Nacional não escrito que lhes dava a Presidência do Líbano, o comando do Exército libanês e outras vantagens em troca da desistência da proteção francesa.

4 Referência ao atentado em Sarajevo, Sérvia, que matou Francisco Ferdinando em 28 de junho de 1914 e desencadeou a Primeira Guerra Mundial (COLLELO, 1989, p. 29 e 190). Sobre a inspiração fascista da Falange, Robert Fisk (2007, p. 109) entrevistou o próprio Pierre Gemayel, que disse: "Eu era capitão da Federação Libanesa de Futebol. Nós fomos aos Jogos Olímpicos de 1936 em Berlim. E eu vi aquela disciplina e ordem. E eu disse para mim mesmo: 'Por que não podemos fazer a mesma coisa no Líbano?' Então, quando voltamos para o Líbano, criamos este movimento de jovens".

5 Ramez Philippe Maalouf (2011, p. 252) leciona que a intervenção síria no conflito, com o ditador Hafez al-Assad não desejando nem a aliança maronita com Israel nem o crescimento do poder palestino revolucionário, foi especialmente desastrosa, já que as tropas sírias tinham as armas pesadas de um exército regular, tendo acabado de travar uma guerra contra Israel, armas cujo uso foi devastador nas concentrações urbanas libanesas.

${ }_{6}$ Para mais detalhes sobre os diversos grupos e facções envolvidos na guerra civil libanesa, e especialmente 
Mas cada lado abrigava uma série de facções e grupos rivais, unidos em coalizões instáveis e disputas intestinas pela proeminência em sua aliança. A inimizade entre os Gemayel e os Franjieh era notória.

Países como Israel, Síria e EUA observavam, com maior ou menor grau de apreensão, a guerra civil se escalando, cada um com seu interesse próprio.

Estima-se que nos dois primeiros anos da guerra civil 44 mil pessoas morreram. A guerra era travada de forma irregular, com combates de guerrilhas e atentados com uso de explosivos, emboscadas e assassinatos seletivos.

Em 1982, relata Mantovani de Lima (2012, p. 172), a situação do Líbano ganhou um complicador adicional:

[...] o governo nacionalista em Israel tentava impor sua própria solução ao problema dos palestinos, o que implicava a tentativa de destruir o poder militar e político da Organização pela Libertação da Palestina (OLP) no Líbano, instalar um regime colaborativo e depois prosseguir com sua política de assentamento e anexação da Palestina ocupada. $^{7}$

Ainda sobre a presença palestina no Líbano nos ensina Ramez Phillipe Maalouf (2011, p. 226):

\begin{abstract}
A marginalização social e política dos expatriados palestinos no Líbano (assim como nos demais países árabes) tornou os campos de refugiados numa fonte de homens armados para os movimentos guerrilheiros, que atacariam Israel a partir da fronteira. Muitos destes ataques recebiam ao mesmo tempo o apoio das resistências laicas (nacionalistas e esquerdistas) árabes à ocupação israelense do território palestino, assim como a repulsa dos que viviam nas zonas fronteiriças em decorrência das represálias de Israel. A presença palestina e sua marginalização social se converteram rapidamente em fatores de instabilidade política para o Líbano.
\end{abstract}

Israel adentrou no Líbano em junho de 1982, cercando Beirute, sendo a primeira vez que tropas israelenses ingressaram numa capital árabe. ${ }^{8}$ Forças israelenses

sobre o número de combatentes de cada milícia, vide Maalouf (2011, p. 238-239).

7 Um dos motivos para a invasão do Líbano foi a tentativa de assassinato do embaixador israelense, Shlomo Argov, por um atirador palestino, no dia 3 de junho de 1982, em Londres, Inglaterra (GILBERT, 2016. p. 550). Israel também respondeu aos crescentes atos de terrorismo palestinos, que incluíam sequestros de aviões, tomadas de reféns e violência dirigida contra civis, e especialmente ao atentado contra atletas israelenses nas Olimpíadas de Munique de 1972.

8 Anita Shapira (2018, p. 457-458) sumariza as motivações israelenses da invasão conforme declaração de 5 de junho de 1982 do primeiro-ministro Menachem Begin: “A alternativa a esta operação é Treblinka [referência a um dos principais campos de extermínio do Holocausto], e nós decidimos que não haverá mais 
enfrentaram tropas do exército sírio e os combatentes palestinos. A OLP terminou se retirando de Beirute ocidental em agosto do mesmo ano, com sua liderança se exilando na Tunísia. ${ }^{9}$

O filho de Pierre Gemayel, Bashir Gemayel, cruel e implacável miliciano, comandante do maior exército privado do Líbano, ascendeu à frente da Falange e, com o apoio de Israel, conseguiu proeminência suficiente para ser eleito presidente do Líbano em 23 de agosto de 1982. ${ }^{10}$ Antes de sua posse, em 14 de setembro de 1982, Bashir foi assassinado durante um ataque a bomba na sede de seu partido. O irmão de Bashir, Amin Gemayel, seria empossado presidente no mesmo ano.

Nos estertores da morte de Gemayel ocorreram os massacres de refugiados palestinos nos campos de Sabra e Chatila, situados em Beirute ocidental, realizados por forças cristãs, motivadas em vingar a morte do presidente eleito, alegadamente com participação e apoio das forças israelenses comandadas por Ariel Sharon (que viria a ser primeiro-ministro de Israel). (COLLELO, 1989, p. 174 e 206). ${ }^{11}$

A retirada da OLP foi monitorada pelos EUA, cujos marines formaram o grosso da tropa multinacional encarregada de supervisionar a evacuação das tropas de Yasser Arafat e proteger posições na capital libanesa. ${ }^{12}$

O conflito continuou pela década de 1980, com uma nova intervenção síria e a chegada ao poder (1988) do general Michel Aoun (MAALOUF, 2011, p. 289).

Treblinkas". Ao público israelense havia sido prometida uma intervenção limitada. Mas a guerra terminaria ganhando maior escala, ainda segundo Shapira (2018, p. 457-458): "A entrada das forças israelenses em Beirute ocidental, após sitiar a cidade por dois meses, tinha por objetivo pressionar Arafat [Yasser Arafat, líder da facção Fatah e da OLP] a se retirar do Líbano sua sede e seus combatentes".

9 Karla Nayra Fernandes Pereira (2015, p. 16) relata a invasão israelense: "Em junho de 1982, depois de intensa troca de tiros ao longo de toda a fronteira com Israel, o Líbano foi novamente invadido por tropas israelenses. Dessa vez, os ataques chegaram aos arredores da capital Beirute. [...] Em 1985, as negociações eram intensas, mas os avanços eram ínfimos. Apesar disso, Israel realizou uma retirada parcial, mas manteve o controle de uma área no sul do Líbano ocupado pelas Forças de Defesa de Israel e por soldados libaneses que havia rompido com o Exército libanês, conhecidos como Exército do Sul do Líbano".

10 Robert Fisk (2007, p. 123) nos conta do que era capaz Bashir Gemayel. Em 1977, ele enviou pistoleiros de sua Falange para a casa de Tony Franjieh, filho de Suleiman Franjieh, este último ex-presidente maronita do Líbano. Além do assassinato de 32 dos seguranças e partidários de Tony Franjieh, este foi forçado a assistir ao fuzilamento de seu bebê e de sua esposa. E, ao fim do macabro ritual, Franjieh foi também morto pelos falangistas.

11 Robert Fisk (2007, p. 489 e 536) estima que, em Chatila, onde esteve pessoalmente após o massacre, teriam morrido de mil a 1,5 mil pessoas, destacando-se a seguinte cena que fotografa para sempre o ocorrido: "Havia bebês - bebês enegrecidos, porque tinham sido chacinados havia mais de 24 horas e seus pequenos corpos já estavam em estado de decomposição [...]". O ultraje com o massacre foi massivo em Israel, gerando uma manifestação de 400 mil pessoas (10\% da população israelense) em Tel Aviv em 25 de setembro de 1982, mostrando a divisão da sociedade sobre a guerra no Líbano e o espírito democrático do país (GILBERT, 2016, p. 556).

12 Os EUA também pagariam preço elevado em vidas no Líbano. Um ataque à base americana em Beirute em 23 de outubro de 1983 mataria 241 americanos (GILBERT, 2016, p. 559). 
Com o advento do Acordo de Taëf (sede de uma base americana na Arábia Saudita), celebrado em 22 de outubro de 1989, o presidente do Líbano (um cristão maronita) passa a dividir seu poder com o primeiro-ministro (um muçulmano sunita) e com o Chefe do Parlamento (um muçulmano xiita), o que permitiu certa normalização política no país. A guerra civil duraria até 13 de outubro de 1990, quando ocorreu a deposição de Michel Aoun, que foi atacado no palácio de Ba'Abda, em ataque em que morreram 700 pessoas. ${ }^{13}$

Em maio de 2000, as forças israelenses se retiraram completamente do sul do Líbano, em obediência à Resolução n. 425 do Conselho de Segurança da ONU - CSONU, que era de 1978 (FISK, 2007, p. 915).

Rafik Hariri, um empresário nascido em 1 de novembro de 1944, em Sidon, Líbano, muçulmano sunita, veria sua fortuna aumentar atuando na reconstrução do país (e especialmente de Beirute), destruído pela guerra civil nos anos 1980 e 1990.

Hariri entraria para a política e se tornaria primeiro-ministro em 1992, ficando no cargo até 1998, assumindo o posto novamente de 2000 a 2004 . Ele foi membro do Parlamento libanês em diversas ocasiões, sendo inclusive parlamentar quando de sua morte.

Em 14 de fevereiro de 2005 ocorre o atentado que mata Hariri e outras 22 pessoas. As suspeitas iniciais recaem sobre agentes da Síria, país ao qual Hariri se opunha durante seus mandatos (LIMA, 2012, p. 173).

\subsection{Os atentados de 2004-2005}

Nos anos 2000, o Líbano voltou a ter um cenário político conturbado, com vozes dissidentes sendo caladas por meio da violência terrorista.

Em 1 de outubro de 2004 uma explosão atingiu o comboio de carros de Marwan Hamadeh (político e jornalista) em Beirute, ferindo ele e seu motorista e matando seu guarda-costas.

Em 14 de fevereiro de 2005, na rua Minet el Hos'n, em Beirute, Rafik Hariri, o ex-Primeiro Ministro do Líbano, foi assassinado num ato terrorista cometido quando um suicida detonou uma grande quantidade de explosivos que estavam escondidos numa van, atingindo o comboio de seis carros de Hariri. A explosão matou Hariri, outras 21 pessoas e feriu outras $226 . .^{14}$

13 Michel Aoun sobreviveu ao golpe e, na data de 8 de abril de 2019, época do fechamento deste artigo, era o Presidente do Líbano (desde 31 de outubro de 2016).

14 A descrição completa do atentado pode ser localizada na seção III - "A Concise Statement of the Facts, Overview", do Indiciamento oferecido pela Promotoria ao TEL (SPECIAL TRIBUNAL FOR LEBANON, 2016c). 
Em 21 de junho de 2005, uma bomba colocada sob o carro de George Hawi (político) explodiu em Beirute, matando Hawi e ferindo seu motorista gravemente.

E em 12 de julho de 2005, outra bomba atingiu o comboio de carros de Elias El-Murr (político) em Antelias, cidade nos arredores de Beirute. Uma pessoa morreu e outras doze, incluindo El-Murr, se feriram.

\section{O Tribunal Especial para o Líbano}

O Conselho de Segurança da ONU, por meio da Resolução n. 1.595, de 7 de abril de 2005 (UNITED NATIONS, 2005a), criou a Comissão de Investigação Independente Internacional da ONU, ou United Nations International Independent Investigation Commission - UNIIIC, comissão com sede no Líbano e com a missão de ajudar as autoridades libanesas na investigação de todos os aspectos do ataque terrorista de 14 de fevereiro de 2005, incluindo identificar os autores, patrocinadores, organizadores e cúmplices. ${ }^{15}$

Atendendo a um pedido do Líbano, o CS-ONU aprovou a Resolução n. 1.644, de 15 de dezembro de 2005 (UNITED NATIONS, 2005b), no sentido de solicitar ao Secretário-Geral da ONU ajuda para criar um tribunal internacional para julgar os responsáveis pelo ataque terrorista de 14 de fevereiro de 2005 e para expandir o mandato da UNIIIC para investigar outros ataques ocorridos a partir de 1 de outubro de 2004 (data do atentado contra o político Marwan Hamadeh).

Foram iniciadas negociações entre a ONU e o Líbano para o estabelecimento de um tribunal internacional. ${ }^{16}$ Entre janeiro e fevereiro de 2007, as Nações Unidas e o Líbano assinaram um acordo para a criação do Tribunal Especial do Líbano.

Mas o Parlamento do Líbano terminou não pondo o acordo em votação e, ao invés disso, solicitou que a ONU votasse uma resolução no Conselho de Segurança sob o Capítulo VII (“Ação Relativa a Ameaças à Paz, Ruptura da Paz e Atos de Agressão”) da Carta da ONU para criar um tribunal especial. ${ }^{17}$

Este pedido foi acatado pela Resolução n. 1.757, de 30 de maio de 2007, do CS-ONU, sob o Capítulo VII da Carta, que contém como anexo o acordo entre ONU

15 Daniel T. P. Runge (2012, p. 105) afirma que o Líbano, quando da criação da UNIIIC, se limitou a aprovar o mandato da comissão e em se comprometer a não interferir com a investigação.

16 Destaque-se aqui o teor da Resolução n. 1.664 do CS-ONU, de 29 de março de 2006, nesse sentido (UNITED NATIONS, 2006).

17 No Brasil, a Carta das Nações Unidas foi promulgada pelo Decreto n. 19.841/1945 (BRASIL, 1945). 
e Líbano (UNITED NATIONS, 2007). ${ }^{18}$ A Holanda concordaria em abrigar a sede do Tribunal. ${ }^{19}$

O Tribunal se situa em Leidschendam, perto da Haia, Holanda, possuindo um escritório em Beirute, Líbano.

O Tribunal não é considerado um tribunal subsidiário da ONU nem um órgão do Poder Judiciário libanês (LIMA, 2012, p. 174).

A UNIIIC chegaria à conclusão de que o assassinato de Rafik Hariri foi realizado por uma rede que teria cometido outros atentados investigados pela própria UNIIIC sob seu mandato estendido de investigação. A UNIIIC encerraria seu mandato em 28 de fevereiro de 2009 (SPECIAL TRIBUNAL FOR LEBANON, 2019). ${ }^{20}$

No dia seguinte, 1 de março de 2009, a Corte iniciou seus trabalhos (TORTORA, 2010, p. 45).

\subsection{Legislação aplicável ao TEL e sua jurisdição}

O TEL foi criado sob os auspícios do Capítulo VII da Carta das Nações Unidas e é regido por um Estatuto - ETEL (SPECIAL TRIBUNAL FOR LEBANON, 2007b), cujo texto foi parte integrante da Resolução n. 1.757 do CS-ONU (UNITED NATIONS, 2007).

A jurisdição original do TEL, segundo o art. $1^{\circ}$ do Estatuto, englobava o julgamento das pessoas responsáveis pelo ataque de 14 de fevereiro de 2005 , que resultou na morte do ex-Primeiro Ministro Rafik Hariri e na morte e ferimento de outras pessoas.

O mesmo artigo prevê que, se o Tribunal concluísse que outros ataques ocorridos no Líbano entre 1 de outubro de 2004 e 12 de dezembro de 2005, especialmente, ou mesmo fora desse período, tivessem relação com o ataque a Rafik Hariri, poderia sua jurisdição ser ampliada para julgar também esses casos.

Uma decisão ${ }^{21}$ do juiz de prejulgamento, de 5 de agosto de 2011, fez com que o TEL reconhecesse que outros três casos tinham conexão com o ataque de 14 de fevereiro de 2005 a Rafik Hariri: os atentados contra os políticos Marwan Hamadeh, George Hawi e Elias El-Murr. ${ }^{22}$

18 Mas Daniel T. P. Runge (2012, p. 107) destaca que o acordo jamais entrou em vigor por falta de aprovação interna no Líbano. O que dá força ao Tribunal é a resolução em comento do CS-ONU, exarada à luz do Capítulo VII da Carta da ONU.

19 Conforme Acordo de Sede neste sentido (KINGDOM OF THE NETHERLANDS; UNITED NATIONS, 2007).

20 Uma das conclusões da UNIIIC, segundo Mantovani de Lima (2012, p. 173), era sobre o envolvimento da cúpula do regime sírio no atentado contra Hariri.

21 Ainda mantida confidencial até o fechamento deste artigo em 8 de abril de 2019.

22 Os casos em comento ainda estão sendo investigados (SPECIAL TRIBUNAL FOR LEBANON, 2019). 
Ou seja, o TEL tem um mandato bem específico e abrange um número bastante limitado de casos (na prática, quatro atentados terroristas ocorridos no Líbano e cometidos por meio de explosivos potentes, e eventualmente algum caso conexo que venha a ser relacionado a estes).

Esse mandato estreito do TEL contrasta, por exemplo, com o escopo de atuação do já extinto Tribunal Penal Internacional para Ruanda - TPIR, cuja competência era julgar as pessoas responsáveis por graves violações do Direito Internacional Humanitário, perpetradas no território de Ruanda, e cidadãos ruandeses que tenham praticado esses crimes no território de Estados vizinhos, abarcando os crimes cometidos entre $1^{\circ}$ de janeiro de 1994 e 31 de dezembro de 1994. Ou seja, um número incalculável de crimes, de diversas espécies, cometidos durante o genocídio ruandês. ${ }^{23}$

Destaque-se também o art. $2^{\circ}$ do Estatuto do TEL, que prevê o direito material aplicável - basicamente, a legislação penal interna libanesa acerca do processo e da punição de atos de terrorismo, crimes contra a vida e contra a integridade física, sedição, guerra civil e conflito inter-religioso. ${ }^{24}$ A combinação destes dois arts. $\left(1^{\circ}\right.$ e $2^{\circ}$ do ETEL) forma a competência material do TEL. ${ }^{25}$

Segundo Daniel T. P. Runge (2012, p. 127), o Código Penal libanês define "terrorismo" como:

atos destinados a criar um estado de alarme, que sejam cometidos por meios como explosivos, materiais inflamáveis, venenosos ou incendiários ou agentes microbiais de forma a criar um risco público. ${ }^{26}$

Note-se aqui a diferença do TEL para outros tribunais penais internacionais. O TEL usa o direito interno libanês como base do direito material aplicável. Já o Tribunal

23 Para mais detalhes sobre a jurisdição do TPIR, vide Módolo de Paula (2014).

24 Note-se que o Estatuto do TEL tempera algumas das disposições do direito libanês, como, por exemplo, não prevendo a aplicação da pena de morte (CRYER; FRIMAN; ROBINSON; WILMSHURST, 2011, p. 188).

25 Quanto à conexão entre os ataques, Renata Mantovani de Lima (2012, p. 180), analisando por sua vez o quarto relatório anual da UNIIIC, chegou às seguintes conclusões: "Ao iniciar suas atividades e investigar as possíveis ligações entre os ataques, a Comissão identificou características convergentes, quais sejam: o funcionamento, ou o padrão de utilização dos engenhos explosivos; a natureza dos crimes ou a intenção criminosa subjacente aos ataques (alvos comuns: políticos ou jornalistas influentes); perpetuação de um clima de medo e ansiedade generalizada entre a população, em função dos ataques serem cometidos em locais públicos; desestabilizando da segurança; danos à infraestrutura e à identidade dos autores. Desse modo, concluíram, preliminarmente, que os 4 casos analisados não poderiam ter sido executados por pessoas ou grupos diferentes, ou mesmo com motivações distintas". Para acesso ao mencionado relatório anual da UNIIIC, vide Special Tribunal for Lebanon (2013).

26 A definição de "terrorismo" sempre é de difícil caracterização legal, lembrando Robert Cryer e outros autores do conhecido e cínico adágio, usado por vezes para justificar os atos mais atrozes: "O terrorista de um é o combatente pela liberdade de outro". O TEL superou este problema simplesmente usando a legislação libanesa sobre o tema (CRYER; FRIMAN; ROBINSON; WILMSHURST, 2011, p. 336-337). 
Penal Internacional para a ex-Iugoslávia, por exemplo, tem como base do direito material tratados internacionais, especialmente a Convenção de Genocídio de 1948 e as quatro Convenções de Genebra de 1949. ${ }^{27}$ O Tribunal Penal Internacional também usa tratados internacionais e a Carta da ONU como base do direito material aplicável. ${ }^{28}$

Quanto à competência temporal do TEL, são os crimes (os quatro atentados já especificados) cometidos entre 1 de outubro de 2004 e 12 de dezembro de 2005.

A competência ratione personae e ratione loci do TEL é julgar as pessoas responsáveis pelos ataques terroristas em questão cometidos no território do Líbano, especialmente em Beirute.

As regras processuais do TEL constam do seu Estatuto - ETEL e do Regulamento Processual - RP, um conjunto de regras processuais editadas pelo próprio Tribunal. ${ }^{29}$

\subsection{Composição e estrutura do TEL}

O TEL é formado por quatro órgãos, conforme art. $7^{\circ}$ do ETEL:

a) as Câmaras, que compreendem um juiz de prejulgamento, uma Câmara de Julgamento (julgamento em primeira instância) e uma Câmara de Apelação (julgamento em segunda instância), onde têm assento os juízes;

b) a Promotoria, encarregada das investigações e das acusações, encabeçada por um promotor;

c) a Secretaria, chefiada por um secretário, encarregado de providenciar apoio administrativo e jurídico às Câmaras e à Promotoria;

d) o Escritório de Defesa, órgão independente cuja existência é novidade em tribunais internacionais (sequer o Tribunal Penal Internacional prevê este órgão em seu Estatuto), que pode ser integrado por defensores públicos, encarregados de garantir os direitos da defesa, providenciar suporte e assistência aos advogados dos réus. ${ }^{30}$

27 Vide Módolo de Paula (2017), especialmente a seção 3.2, "Legislação aplicável ao TPII".

28 Vide artigos 5 a 8 bis do Estatuto do TPI sobre o direito aplicável, especialmente o art. 8 bis, que versa sobre o crime de agressão, que por sua vez prevê a utilização da Carta da ONU e da Resolução n. 3.314 (XXIX), de 14 de dezembro de 1974, para a definição de um ato de agressão (BRASIL, 2002).

29 Em inglês, o RP é chamado de "Rules of Procedure and Evidence" (SPECIAL TRIBUNAL FOR LEBANON, 2017). A autorização para sua edição consta do art. 28 do ETEL. A última versão foi adotada pelo TEL em 3 de abril de 2017 e, exceto menção em contrário, foi a versão utilizada neste artigo. Adotou-se o termo "Regulamento Processual" em consonância com o Decreto Federal n. 4.388, de 2002, que promulgou o Estatuto de Roma do Tribunal Penal Internacional no Brasil.

$30 \mathrm{O}$ art. 13 do ETEL prevê como é a atuação do Escritório da Defesa e especifica suas funções. Ressalve-se que o titular do Escritório de Defesa ou seus funcionários não representam os acusados. O titular do órgão apenas nomeia ou designa advogados para tanto. 
Sobre os juízes e Câmaras do TEL, merecem menção as seguintes regras sobre a escolha dos juízes e composição das Câmaras, conforme arts. $8^{\circ}$ e $9^{\circ}$ do ETEL:

a) O juiz de prejulgamento é um juiz internacional, que não integrará outras Câmaras nem participará de outras fases do processo;

b) A Câmara de Julgamento é composta por três juízes, sendo um libanês e dois internacionais;

c) A Câmara de Apelação é composta por cinco juízes, sendo dois libaneses e três internacionais;

d) Dois juízes, um libanês e outro internacional, serão juízes suplentes.

Os juízes são indicados pelo Secretário-Geral da ONU, consultado o Líbano, para um mandato de três anos, sendo possível a recondução, devendo ser pessoas de alta qualidade moral, imparcialidade, integridade e extensa experiência judicial, de preferência em direito penal, processual penal e internacional. ${ }^{31}$

O Presidente do Tribunal é o juiz presidente da Câmara de Apelação. ${ }^{32}$

Os mesmos critérios de escolha dos juízes são usados para a seleção do Promotor da corte, que será escolhido pelo Secretário-Geral da ONU, com consulta ao Líbano, para um mandato de três anos, passível de recondução, e terá a assistência de um promotor-adjunto libanês. ${ }^{33}$

A Secretaria será chefiada por um Secretário, igualmente nomeado pelo Secretário-Geral da ONU para um mandato de três anos, prorrogável, sendo o órgão responsável pela administração e demais serviços do TEL.

A Unidade de Vítimas e Testemunhas é vinculada à Secretaria, sendo órgão encarregado de assegurar o bem-estar físico e psicológico de vítimas e testemunhas. ${ }^{34}$

As línguas oficiais do TEL são o árabe, o inglês e o francês, podendo uma ou duas destas serem usadas como língua de trabalho. ${ }^{35}$

Quanto ao orçamento do TEL, o Acordo de criação prevê que 51\% do orçamento é oriundo de contribuições voluntárias de Estados-membros da ONU e o resto das despesas são ônus do estado do Líbano, com previsão de meios alternativos de financiamento em sendo necessário. ${ }^{36}$

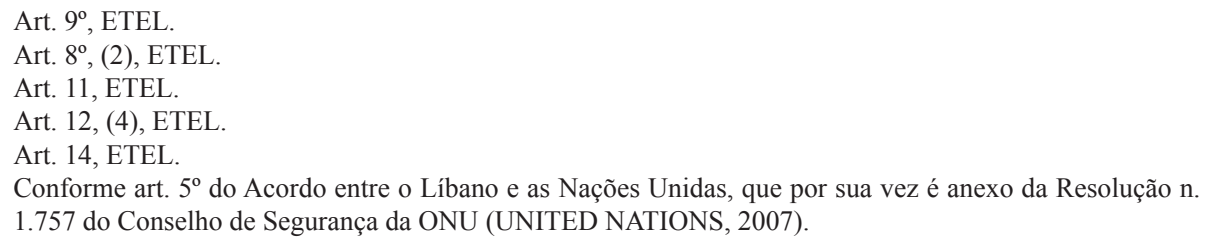


Em cada ano de funcionamento do Tribunal, conforme consulta ao site da Corte, ${ }^{37}$ seu orçamento anual foi o seguinte (em milhões de euros):

\begin{tabular}{c|c}
\hline Ano & $\begin{array}{c}\text { Orçamento } \\
\text { (€ milhões) }\end{array}$ \\
\hline 2009 & 51,4 \\
2010 & 55,4 \\
2011 & 65,7 \\
2012 & 55,3 \\
2013 & 59,9 \\
2014 & 59,89 \\
2015 & 59,87 \\
2016 & 62,8 \\
2017 & 59,0 \\
2018 & 58,8 \\
2019 & 55,1 \\
\hline
\end{tabular}

Estes onze anos de orçamento do TEL (2009-2019) totalizam um gasto de 643,16 milhões de euros até o fim do ano de 2019. Guardemos estes dados para a conclusão do artigo.

\subsection{Fases do processo e outros aspectos dos procedimentos no Tribunal}

No TEL, o processo se subdivide em prejulgamento, julgamento e apelação.

O Promotor apresentará seu indiciamento (acusação escrita) ao juiz de prejulgamento, que o analisará e, concordando que existem elementos para o prosseguimento da ação, poderá confirmar o indiciamento. Não havendo elementos, o indiciamento será indeferido. ${ }^{38}$

Este mesmo juiz possui o poder de ordenar prisões e transferências de pessoas, e quaisquer outras medidas necessárias para a condução das investigações e para a preparação de um julgamento expedito. ${ }^{39}$

Com o indiciamento do(s) acusado(s), inicia-se a fase de julgamento. Numa audiência com a presença do acusado, a Câmara de Julgamento lerá o indiciamento, verificará o respeito aos direitos do acusado, confirmará se ele compreende a acusação e abrirá uma oportunidade para que se declare culpado ou inocente. ${ }^{40}$

37 Cada um dos relatórios anuais, constando o respectivo orçamento anual, pode ser consultado em Special Tribunal for Lebanon (s.d.).

38 Art. 18, (1), ETEL.

39 Art. 18, (2), ETEL.

40 Art. 20, (1), ETEL. Caso o réu se declare culpado será seguido o procedimento previsto nos arts. 99 e 100 do RP, no qual se verifica se a declaração de culpa é livre e voluntária, informada, inequívoca e fundada em evidência da existência do crime e da participação do acusado, com participação e consulta ao seu 
Um diferencial do TEL é a possibilidade de julgamentos à revelia (in absentia), previsto no art. 22 do ETEL para algumas hipóteses como, por exemplo, renúncia do acusado do direito de estar presente, sua fuga ou não entrega pelas autoridades competentes. $^{41}$

O Regulamento Processual trata das provas que são admitidas no TEL, sua produção, e normatiza a ordem dos procedimentos a serem seguidos durante as audiências de instrução, bem como as formas de manifestação da Promotoria e da defesa. ${ }^{42}$

Ao fim da instrução a Câmara de Julgamento se reunirá, em data certa e em sessão pública, para deliberar em apartado, a fim de analisar as acusações. ${ }^{43}$

É feita uma votação para cada acusação, exigida a maioria dos juízes da Câmara de Julgamento em cada votação. Sendo o acusado culpado de uma ou mais acusações, será estipulada a pena cabível e a sua forma de cumprimento, podendo uma única sentença refletir a totalidade das condutas do acusado. ${ }^{44}$

As penas a serem aplicadas pelo TEL são unicamente de prisão, podendo esta ser por um determinado período ou perpétua. ${ }^{45}$ Mas as vítimas podem receber compensações dos responsáveis, nos termos do art. 25 do ETEL, em tribunais nacionais.

As decisões proferidas pela Câmara de Julgamento podem ser reformadas pela Câmara de Apelação. Esta Câmara revê apenas as decisões da Câmara de julgamento do próprio TEL, e não de outras jurisdições nacionais ou tribunais internacionais. ${ }^{46}$

Existe também um procedimento de revisão, usado em casos de surgimento de fatos novos que possam alterar a conclusão de uma das Câmaras. ${ }^{47}$

advogado. Neste caso, o processo estará pronto para ser sentenciado.

41 As regras para julgamento à revelia constam no art. 22 do ETEL, que preveem que ele seja sempre assistido por um advogado de sua escolha ou indicado pelo Escritório de Defesa, que acompanhará o caso até o julgamento de apelação. Em caso de condenação, o acusado poderá ser julgado novamente com sua presença perante o TEL, a não ser que ele aceite o julgamento. O problema desta regra é que ela não faz distinção entre, de um lado, casos em que possa ter havido de fato uma nulidade ou prejuízo à defesa com a ausência do acusado no próprio julgamento e, de outro, casos em que o direito de defesa do acusado foi plenamente respeitado, mesmo com o julgamento à revelia. Ora, o TEL já existe há dez anos e ainda não julgou nenhum dos dois casos principais que tramitam na Secretaria. Na hipótese de uma condenação, caso algum dos acusados de fato comparecesse perante a Corte e solicitasse um novo julgamento, por quanto mais tempo se prorrogaria a existência do TEL? A regra, em tese, é benéfica aos acusados, mas bastante custosa para os financiadores do Tribunal (em especial o Líbano) e muito prejudicial às vítimas sobreviventes e parentes dos que foram assassinados nos atos terroristas, que já esperam pelo julgamento há mais de uma década.

42 Tais regras constam especialmente nos arts. 149 a 166 do RP.

43 Art. 23 do ETEL e art. 168, (A), do RP.

44 Art. 23 do ETEL e arts. 168, (B) e 171, (D), do RP. Eventual acusado absolvido das acusações será sujeito às regras do art. 170 do RP (se algum destes acusados estiver preso, será imediatamente libertado).

45 Art. 24, (1), ETEL, e art. 172 do RP, que preveem ainda os parâmetros e a dosimetria das penas aplicadas. Note-se que, no caso de desacato ou obstrução de justiça, pode ser aplicada prisão ou pena de multa (art. 60 , bis, [J], RP).

46 Art. 26, ETEL, e arts. 176 a 189, RP (procedimento da apelação).

47 Conforme art. 27, ETEL, e arts. 190 a 193 do RP. 
Sobre o cumprimento da pena, conforme o art. 29 do ETEL, as prisões podem ser cumpridas num Estado indicado pelo Presidente da Corte dentre uma lista de Estados que colaboram com esta. ${ }^{48}$

O TEL depende, para seu funcionamento, da colaboração internacional, e especialmente do país no qual ocorreram os fatos investigados, o Líbano. A forma desta colaboração é prevista nos arts. 13 a 23 do Regulamento Processual do TEL, que prevê regras para atendimento de pedidos da Promotoria e do Escritório de Defesa, para cumprimento de ordens judiciais e para regulamentação de situações nas quais o Líbano não atende a ordens da Corte.

O Estatuto do TEL e seu Regulamento Processual asseguram uma série de direitos aos suspeitos e acusados, aplicáveis durante a fase de investigação e durante o julgamento em qualquer Câmara, conforme os art. 15 e 16 do ETEL e arts. 61 a 67 do RP.

As vítimas também têm direitos na Corte, como o de serem ouvidas durante os procedimentos, e, especialmente, de serem protegidas, inclusive com adoção de medidas de resguardo de sua identidade. ${ }^{49}$

$\mathrm{O}$ art. 30 do ETEL prevê a possibilidade de perdão ou comutação das sentenças de condenação. Esses institutos dependem da legislação do Estado no qual o condenado esteja cumprindo sua pena..$^{50}$

\subsection{Os casos em andamento no Tribunal Especial para o Líbano}

Atualmente no TEL tramitam duas ações principais. ${ }^{51}$

a) Ação relativa a três ataques conexos ao atentado contra Rafik Hariri (STL-11-02 - vítimas principais: Marwan Hamadeh, George Hawi e Elias El-Murr). Esta ação sequer possui ainda indiciamento e está em fase de investigação;

b) Ação Ayyash e Outros (STL-11-01), relacionada ao assassinato de Rafik Hariri e outras vítimas colaterais em 14 de fevereiro de 2005. Esta ação é conhecida pelo sobrenome do principal acusado sobrevivente, o senhor Salim Jamil Ayyash. ${ }^{52}$

48 Art. 29, (1), ETEL.

49 Art. 17, ETEL, e arts. 86, 87 e 133, RP. Segundo Cryer, Friman, Robinson e Wilmshurst (2011, p. 480-481), estas disposições sobre direitos das vítimas no TEL teriam influência do direito francês.

50 Regras adicionais sobre o tema constam nos arts. 194 a 196 do RP.

51 Não analisaremos dois casos já julgados pelo TEL de interferência na instrução (contempt of the Tribunal Hipóteses relacionadas a falso testemunho, ameaças ou tentativas de suborno às vítimas ou às testemunhas, Art. 60, bis, RP), movidos contra certos indivíduos e empresas de mídia (STL-14-05 e STL-14-06). Detalhes sobre estas ações podem ser encontrados no site do TEL (SPECIAL TRIBUNAL FOR LEBANON, 2018).

52 Um outro acusado, Mustafa Amine Badreddine, teria participado do atentado, sendo considerado seu 
Como a ação Ayyash e Outros é a única que possui material que pode ser analisado (o indiciamento, decisões judiciais interlocutórias pertinentes e o andamento processual), é nela que concentraremos nossa análise acerca do trabalho realizado até o momento pelo TEL.

Os quatro acusados desta ação são Salim Jamil Ayyash, Hassan Habib Merhi, Hussein Hassan Oneissi e Assad Sabra Hassan, que seriam membros do grupo Hezbollah. ${ }^{53}$

Segundo Renata Mantovani de Lima (2012, p. 176):

A Câmara de Julgamento concluiu que todas as medidas razoáveis foram tomadas para garantir a presença dos acusados e notificá-los das acusações contra eles. [...] no dia 30 de junho de 2011, o Tribunal expediu mandados de prisão [contra os então cinco acusados], a serem cumpridos pelas autoridades libanesas [...].

Os quatro acusados sobreviventes jamais foram capturados. ${ }^{54}$ Ao longo dos anos, o TEL tomou decisões no sentido de unificar as ações contra os acusados e pela admissibilidade de seu julgamento à revelia. ${ }^{55}$

Em 12 de julho de 2016 foi apresentada pela Promotoria do TEL uma versão consolidada do indiciamento contra os quatro réus vivos. ${ }^{56}$ Alguns dos trechos do indiciamento permanecem sigilosos até hoje.

organizador, mas teria morrido em maio de 2016, razão pela qual foi excluído da ação da Promotoria. Sobre o encerramento do processo contra Badreddine, vide Special Tribunal for Lebanon (2016b).

53 O Hezbollah (em árabe "Partido de Alá" ou "Partido de Deus") é organização militar e política do Líbano, xiita, apoiada pelo Irã e pela Síria, considerada um grupo terrorista pela maioria do Ocidente, Israel e diversos países árabes. As atividades do Hezbollah são financiadas por uma gama de atividades criminosas que incluem sequestros, extorsão e tráfico internacional de drogas. Sua atuação é global e se estende até a América Latina (RAATZ, 2018). Leonardo Coutinho (2018), em seu livro sobre o presidente venezuelano Hugo Chávez, relata as atividades perniciosas do Hezbollah na América Latina, especialmente os atentados cometidos pelo grupo na Embaixada de Israel em Buenos Aires em 1992 e na sede da entidade judaica Associação Mutual Israelita Argentina - Amia, também na capital argentina, em 1994, atentados que deixaram dezenas de mortos e que tiveram envolvimento de agentes iranianos.

54 Pelo menos até 8 de abril de 2019, data do fechamento deste artigo.

55 Sobre a decisão do TEL pelo julgamento in absentia dos acusados, vide Special Tribunal for Lebanon (2012). A Câmara de Julgamento (SPECIAL TRIBUNAL FOR LEBANON, 2012b) afirmou em sua decisão que as autoridades libanesas tentaram várias vezes localizar os acusados em seus endereços conhecidos, locais de trabalho e casas de familiares, e consideraram que a publicidade dos acusados e do caso no Líbano foi massiva. A própria Câmara de Julgamento manteria sua decisão nesta seara em pedido de reconsideração da Defesa (SPECIAL TRIBUNAL FOR LEBANON, 2012c). Esta decisão pode ser conferida da seguinte forma: SPECIAL TRIBUNAL FOR LEBANON, 2012d.

56 O indiciamento está disponível em Special Tribunal for Lebanon (2016c). O indiciamento original é de 17 de janeiro de 2011 (SPECIAL TRIBUNAL FOR LEBANON, 2016a). Dois anexos do indiciamento contêm a lista das demais vítimas do atentado contra Hariri, com muitos nomes de vítimas jamais revelados pela Corte. 
Os quatro acusados foram indiciados, no total, por nove acusações, sendo uma comum para os quatro réus (conspiração para cometimento de atos terroristas); quatro das acusações dizem respeito exclusivamente ao acusado Salim Jamil Ayyash (ligadas ao ato terrorista contra Rafik Hariri e outras vítimas) e quatro acusações contra os demais acusados (cumplicidade nos atos cometidos pelo Sr. Ayyash) (SPECIAL TRIBUNAL FOR LEBANON, 2016c, seção "Preamble").

$\mathrm{O}$ indiciamento descreve a conduta de cada um dos quatro acusados e sua participação na autoria do atentado, com pormenorizada descrição de seus atos e sua tipificação segundo a legislação penal considerada como base no Estatuto do TEL (especialmente a legislação penal interna libanesa acerca do processo e punição de atos de terrorismo, crimes contra a vida e integridade física, sedição, guerra civil e conflito inter-religioso).

A Promotoria analisa no indiciamento as redes de telefones móveis usados para planejar e coordenar o ataque que matou Hariri e as outras vítimas, apontando a existência de cinco redes de telefonia celular utilizadas pelos acusados.

Alguns dos usuários dos telefones jamais foram identificados pela Promotoria e são referidos pela letra S seguida de um ou dois algarismos (ex.: S5, S10) (SPECIAL TRIBUNAL FOR LEBANON, 2016c, seção "Phone Networks Involved in the Attack").

Na seção "Chronology of the Attack" do indiciamento é feita uma descrição pormenorizada dos atos dos acusados e demais cúmplices não identificados desde a preparação do ataque até seu cometimento, com destaque especial para os eventos do próprio dia do atentado contra Hariri, no qual alguns dos acusados teriam se posicionado em diversos pontos da rota utilizada pelo comboio de Rafik Hariri para emboscá-lo de forma covarde (SPECIAL TRIBUNAL FOR LEBANON, 2016c, seção “Chronology of the Attack").

O planejamento do atentado teria começado quase quatro meses antes do dia fatal, com a tocaia de Rafik Hariri para fins de estudo de seus hábitos e segurança tendo começado em 20 de outubro de 2004. Durante todo esse período os conspiradores permaneceram em ativa comunicação telefônica (SPECIAL TRIBUNAL FOR LEBANON, 2016c, seção "Chronology of the Attack").

Daniel T. P. Runge, com base no primeiro indiciamento da Promotoria, apresentou qual era o papel de cada um dos acusados no atentado contra Hariri. O finado Mustafa Badreddine era o cérebro por trás do plano. Salim Ayyash coordenou o time de 
ataque a Hariri. Os acusados Hussein Hassan Oneissi e Assad Sabra Hassan ainda teriam tentado forjar pistas falsas a fim de atrapalhar as iminentes investigações das autoridades libanesas, como contatar órgãos da mídia para contar acerca da existência de uma fita de vídeo na qual um falso terrorista suicida afirmava ser responsável pelo atentado (RUNGE, 2012, p. 115).

Ao final do indiciamento, o Promotor Norman Farrell (Canadá) recapitula as acusações e crimes cometidos por cada um dos quatro acusados (SPECIAL TRIBUNAL FOR LEBANON, 2016c, seção "The Conspiracy”).

Desde o primeiro indiciamento, em 2011, a Corte realizou audiências de instrução, coletou provas e ouviu testemunhas.

Em agosto e setembro de 2017, representantes das vítimas apresentaram seu caso. Em 7 de fevereiro de 2018 foi a vez de a Promotoria encerrar suas alegações. Neste mesmo ano a Defesa começou a produzir suas provas. No fim de 2018 as alegações finais das duas Partes e das vítimas foram apresentadas.

O feito aguarda a prolação de sentença pela Câmara de Julgamento, que absolverá todos ou alguns dos réus.

O trabalho do TEL continuará a fim de julgar eventual ação movida pela Promotoria contra os responsáveis pelos demais atentados objeto da atuação da Corte, para julgar eventuais pedidos de novo julgamento em caso de comparecimento dos acusados ora revéis, e eventuais apelações e revisões contra as sentenças das Câmaras.

\section{Conclusões}

Não se discute a importância de tribunais penais internacionais, seja o TPI permanente, criado pelo Estatuto de Roma, sejam os diversos tribunais ad hoc (Iugoslávia, Ruanda, Líbano etc.). Nesta linha é a lição do juiz da Corte Internacional de Justiça Antônio Augusto Cançado Trindade (2013, p. 109):

Assim como os tribunais internacionais têm afirmado a responsabilidade dos perpetradores de violações do direito internacional, do mesmo modo se sentem, eles próprios, responsáveis em relação às vítimas, que a eles recorrem à busca da justiça. A asserção da responsabilidade - com todas as suas consequências jurídicas - tem exercido um papel-chave na luta contra a impunidade. Em qualquer parte do mundo, reconhece-se hoje que os perpetradores de violações graves dos direitos humanos (Estados ou indivíduos), assim como os responsáveis por atos de genocídio, crimes de guerra e crimes contra a humanidade, devem responder judicialmente pelas atrocidades cometidas, independentemente de sua nacionalidade ou nível hierárquico na escala do poder público estatal. 
A importância do TEL ainda abrange um componente diverso daquela dos tribunais encarregados de julgar crimes contra a humanidade, genocídio etc.

Em verdade, Daniel T. P. Runge (2012, p. 104) indaga se o TEL poderá servir de modelo para outros tribunais ad hoc encarregados de julgar atos terroristas, crime que a comunidade internacional a muito custo tem buscado formas de enfrentar e prevenir.

Não há resposta fácil para o terrorismo, crime grave que tem por elementos a radicalização política e religiosa, cometido por vezes por autores que sequer se preocupam em preservar sua própria vida ou incolumidade física nos atos criminosos.

Os executores dos atentados são geralmente jovens tolos e sem perspectiva na vida, facilmente manipulados por ideólogos que sequer se arriscam nos atentados, como é o caso do falecido Mustafa Badreddine, que encontrou um fantoche anônimo para se explodir e cometer o magnicídio contra Rafik Hariri.

Se terroristas sequer cuidam de preservar a própria vida, como acreditar que um tribunal local ou internacional atuará como um impeditivo à sua atuação?

O foco desses tribunais deveria ser também garantir que os cérebros por trás dos ataques sejam punidos, quiçá com instrumentos para asfixiar financeiramente os grupos extremistas que comandam e punir os Estados que os apoiam. Mas estas medidas também dependeriam de poderes adicionais para esses tribunais, que iriam além das meras medidas de processo penal contra acusados de terrorismo.

No caso, o Tribunal Especial para o Líbano punirá na melhor das hipóteses um pequeno punhado de terroristas. Mas quem deu de fato a ordem para o assassinato de Rafik Hariri e demais políticos atacados? Serão os políticos libaneses, sírios e iranianos envolvidos nos atentados punidos pela Corte? Sofrerá o Hezbollah o necessário castigo, ou ao menos serão eles alijados da vida política do Líbano, como deveriam ser?

Já sabemos que a resposta será negativa, pelo menos da forma que tramitam os processos no TEL, que possui mandato e poderes bem limitados.

Quanto à ideia em si da criação de um tribunal internacional ad hoc para julgar atos terroristas, não há reparos. O que pode ser ponderado é quantas cortes deste jaez seriam necessárias para coibir de fato o terrorismo internacional e a que preço? Está o mundo disposto a pagar pelo funcionamento das dezenas de cortes que seriam necessárias? Ou estaria já madura a ideia de criar uma corte permanente, nos moldes do TPI, para julgar exclusivamente casos de terrorismo? Uma corte nestes moldes precisa de poderes, além dos poderes de um juízo criminal, para de fato sancionar os grupos terroristas, seus financiadores e Estados patrocinadores do terrorismo.

Como fecho deste raciocínio, um reparo que é preciso ser feito em relação à atuação do Tribunal Especial para o Líbano é o seu custo até o momento. 
Como vimos acima, o Tribunal, com sua estrutura administrativa, custou de 2009 a 2019, 643,16 milhões de euros. ${ }^{57}$

Somos da mesma opinião do Professor Wagner Menezes (2013, p. 245-246) de que uma única solução pacífica de um conflito tem um valor incalculável em razão das vidas humanas que podem ser poupadas, e que os mesmos que questionam o custo de manutenção de um tribunal internacional não questionam quanto os Estados gastam em armas ou em exercícios bélicos e para a destruição.

Mas podemos sim questionar um gasto de mais de 600 milhões de euros para o funcionamento de um único Tribunal, uma corte que em mais de dez anos de efetivo funcionamento ainda não prolatou sentença no principal caso que analisa; sentença esta que será dificilmente cumprida eis que os réus continuam foragidos.

Na prática, metade dos gastos do Tribunal são arcados pelo Líbano, país bastante carente e que poderia ter usado estes fundos melhor - como, por exemplo, na reconstrução da infraestrutura do país, jamais plenamente recuperada da guerra civil dos anos 1970-1980, ou mesmo, para ficarmos no escopo de atuação do Tribunal, na prevenção da radicalização que leva a atos terroristas ou na educação política para uma melhor convivência entre as etnias e religiões do país.

De qualquer modo, a experiência do TEL permite uma evolução da forma como a sociedade global pune o terrorismo internacional, especialmente nos aspectos da coleta de provas.

O trabalho da Promotoria do TEL na investigação do atentado, especialmente no aspecto da análise das redes de telefonia dos perpetradores do atentado contra Rafik Hariri, foi admirável e primoroso.

Mas, por ora, não podemos concluir que o julgamento à revelia, sem prisões, de um petit comité de terroristas radicalizados ligados a uma das mais ferozes milícias criminosas do mundo, o Hezbollah, que faz do assassinato seletivo e do terror o seu modus operandi, dissuadirá os criminosos do futuro que queiram agir da mesma forma.

É até de se questionar se o Líbano de fato conseguiu pôr todo o seu apoio e peso no trabalho de um tribunal que investiga atos de integrantes de uma de suas principais facções políticas, já que o Hezbollah é uma entidade que tanto atua politicamente (com representantes no Parlamento libanês e em outros órgãos públicos) quanto fora dos canais oficiais, com organização militar e paramilitar e criminosa (tráfico de drogas, terrorismo, assassinatos políticos).

Um político do Parlamento libanês tem de fato liberdade de se opor à existência do Hezbollah, ou criticar a influência do Irã ou da Síria na política interna de

57 Ou 2,836 bilhões de reais, considerado o câmbio do euro comercial de R\$ 4,41 na data de 31 de março de 2019. 
seu país? Pode este parlamentar propor estender uma mão de paz na direção de Israel, algo que faria com que seu país poupasse recursos usados em gastos militares sem necessidade?

Ou este hipotético político logo encontraria o mesmo destino de Rafik Hariri, sendo atacado em plena luz do dia por pistoleiros ou terroristas suicidas?

A tolerância do Líbano com a participação do Hezbollah na sua vida política é contraditória. O grupo terrorista tem assentos no Parlamento libanês, mas, ao mesmo tempo, comete atos terroristas contra civis indefesos, no Líbano e fora dele, com seu braço dito "militar". É impossível separar os dois "lados" do Hezbollah.

Quiçá um tribunal de fato internacional, sem tanta participação do país no qual ocorreram os fatos investigados pelo TEL, poderia ter obtido melhores resultados (ou ao menos mais céleres).

Enfim, serve este breve artigo como forma de provocar discussões adicionais sobre a repressão internacional ao terrorismo e quanto à forma de funcionamento e custos de tribunais internacionais.

São Paulo, abril de 2019.

\section{Referências}

BRASIL. Decreto n. 4.388, de 25 de setembro de 2002. Promulga o Estatuto de Roma do Tribunal Penal Internacional. Portal do Planalto, Brasília, DF., set. 2002. Disponível em: http://www. planalto.gov.br/ccivil_03/decreto/2002/D4388.htm.

BRASIL. Decreto n. 19.841, de 22 de outubro de 1945. Promulga a Carta das Nações Unidas, da qual faz parte integrante o anexo Estatuto da Corte Internacional de Justiça, assinada em São Francisco, a 26 de junho de 1945, por ocasião da Conferência de Organização Internacional das Nações Unidas. Portal do Planalto, Brasília, DF., out. 1945. Disponível em: http://www.planalto. gov.br/ccivil_03/decreto/1930-1949/D19841.htm.

BUNTON, Martin. The Palestinian-Israeli conflict: a very short introduction. Oxford: Oxford University Press, 2013.

COLLELO, Thomas (ed.). Lebanon: a country study. 3. ed. Washington, DC: Headquarters, Department of the Army, 1989.

COUTINHO, Leonardo. Hugo Chávez, o espectro: como o presidente venezuelano alimentou o narcotráfico, financiou o terrorismo e promoveu a desordem global. São Paulo: Vestígio, 2018.

CRYER, Robert; FRIMAN, Håkan; ROBINSON, Darryl; WILMSHURST, Elizabeth. An introduction to international criminal law and procedure. 2. ed. Cambridge: Cambridge University Press, 2011. 
DJAHJAH, Fernanda Resende. Estudo comparativo sobre instrumentos de participação política nos direitos brasileiro e libanês. 2013. (Mestrado em Ciências Jurídicas) - Departamento de Direito - PUC-Rio, Pontifícia Universidade Católica do Rio de Janeiro, Rio de Janeiro, 2013. Disponível em: https://www.maxwell.vrac.puc-rio.br/Busca_etds.php?strSecao=resultado\&nrSeq=23210@1. Acesso em: 4 abr. 2019.

FISK, Robert. Pobre nação. Tradução Vitor Paolozzi. Rio de Janeiro: Record, 2007.

GILBERT, Martin. História de Israel. Lisboa: Edições 70, 2016.

LIMA, Renata Mantovani de. Tribunais híbridos e justiça internacional penal. Belo Horizonte: Arraes, 2012.

MAALOUF, Ramez Philippe. Geoestratégias em confronto no Libano em guerra (1975-90). 2011. Dissertação (Mestrado em Geografia Humana) - Faculdade de Filosofia, Letras e Ciências Humanas, Universidade de São Paulo, São Paulo, 2011.

MENEZES, Wagner. Tribunais internacionais: jurisdição e competência. São Paulo: Saraiva, 2013.

PAULA, Luiz Augusto Módolo de. Genocídio e o tribunal penal internacional para Ruanda. Curitiba: Appris, 2014.

PAULA, Luiz Augusto Módolo de. Resolução de conflitos em direito internacional público e a questão Iugoslava. Belo Horizonte: Arraes, 2017.

PEREIRA, Karla Nayra Fernandes. A participação do Brasil na Força Interina das Nações Unidas no Líbano. 2015. Conclusão de Curso (Especialização em Relações Internacionais) - Instituto de Relações Internacionais, Universidade de Brasília, Brasília, 2015.

RAATZ, Luiz. Elo entre Hezbollah e tráfico na América Latina preocupa EUA. O Estado de São Paulo, 13 dez. 2018. Disponível em: https://internacional.estadao.com.br/noticias/geral,elo-entrehezbollah-e-trafico-na-america-latina-preocupa-eua,70002643847. Acesso em: 8 mar. 2019.

RUNGE, Daniel T. P. The special tribunal for Lebanon's unique beginnings, its political opposition and role as model for future ad hoc criminal tribunals for terrorism prosecution. Southwestern Journal of International Law, Los Angeles, v. 19, n. 1, p. 103-132, 2012.

SALOMÃO, Wiliander França. The Israeli-Palestinian conflict: code of treaties and laws. Belo Horizonte: D'Plácido, 2017.

SHAPIRA, Anita. Israel: uma história. Tradução Debora Fleck e Samuel Feldberg. São Paulo: Paz e Terra, 2018.

SPECIAL TRIBUNAL FOR LEBANON. Agreement between the Kingdom of the Netherlands and the United Nations concerning the Headquarters of the Special Tribunal for Lebanon. 21 dez. 2007a. Disponível em: http://oldltd.mithyalabs.com/en/doc/b236ff/pdf/. Acesso em: 28 fev. 2019. 
SPECIAL TRIBUNAL FOR LEBANON. Annual reports. [20--]a. Disponível em: https://www.stltsl.org/en/documents/president-s-reports-and-memoranda. Acesso em: 31 mar. 2019.

SPECIAL TRIBUNAL FOR LEBANON. Before the trial chamber. Decision on reconsideration of the trial in absentia decision. July 2012d. Disponível em: https:/www.legal-tools.org/doc/6fed35/ pdf/. Acesso em: 1 mar. 2019.

SPECIAL TRIBUNAL FOR LEBANON. Before the trial chamber. Decision to hold trial in absentia. Feb. 2012b. Disponível em: https://www.stl-tsl.org/crs/assets/Uploads/20120201_F0112_ PUBLIC_TC_Decision_Trial_inAbsentia_Filed_EN.pdf. Acesso em: 1 mar. 2019.

SPECIAL TRIBUNAL FOR LEBANON. Before the trial chamber. Prosecution submission of the consolidated amended indictment pursuant to the trial chamber's order of 11 July 2016. July 2016a. Disponível em: https://www.stl-tsl.org/crs/assets/Uploads/20160712_F2640_PUBLIC_OTP_ Subm_Cons_Amend_Indictment_EN_Web.pdf. Acesso em: 27 fev. 2019.

SPECIAL TRIBUNAL FOR LEBANON. Before the trial chamber. Redacted version of the amended consolidated indictment. July 2016c. Disponível em: https:/www.stl-tsl.org/crs/assets/ Uploads/20160712_F2640_PUBLIC_A03_OTP_Subm_Cons_Amend_Indictment_EN_Web.pdf. Acesso em: 4 abr. 2019.

SPECIAL TRIBUNAL FOR LEBANON. Contempt cases. [20--]b. Disponível em: https://www. stl-tsl.org/en/the-cases/contempt-cases. Acesso em: 25 fev. 2019.

SPECIAL TRIBUNAL FOR LEBANON. Fourth Annual Report 2012-2013. [20--]c. Disponível em: https:/www.stl-tsl.org/en/documents/president-s-reports-and-memoranda/2181-fourth-annualreport-2012-2013. Acesso em: 1 mar. 2019.

SPECIAL TRIBUNAL FOR LEBANON. In absentia proceedings. Fev. 2012a. Disponível em: https://www.stl-tsl.org/en/media/press-releases/1371-in-absentia-proceedings. Acesso em: 28 fev. 2019.

SPECIAL TRIBUNAL FOR LEBANON. Rules of procedure and evidence. Mar. 2009. Disponível em: https://www.stl-tsl.org/en/documents/legal-documents/rules-of-procedure-and-evidence. Acesso em: 4 abr. 2019.

SPECIAL TRIBUNAL FOR LEBANON. Statute of the special Tribunal for Lebanon. May $2007 \mathrm{~b}$. Disponível em: https://www.stl-tsl.org/en/documents/legal-documents/statute-of-the-tribunal. Acesso em: 4 abr. 2019.

SPECIAL TRIBUNAL FOR LEBANON. STL timeline of events. [20--]d. Disponível em: https:// www.stl-tsl.org/en/about-the-stl/636-creation-of-the-stl. Acesso em: 25 fev. 2019. 
SPECIAL TRIBUNAL FOR LEBANON. The appeals chamber. Decision on badreddine defence interlocutory appeal of the "interim decision on the death of Mr. Mustafa amine badreddine and possible termination of proceedings". July 2016b. Disponível em: https:/www.stl-tsl.org/crs/assets/ Uploads/20160711_F0019_PUBLIC_AC_Dec_Badred_Appeal_re_TC_Int_Dec_Death_of_ Badred_Filed_EN_Joomla.pdf?. Acesso em: 1 mar. 2019.

SPECIAL TRIBUNAL FOR LEBANON. Trial chamber dismisses motions to reconsider in absentia proceedings. July 2012c. Disponível em: https:/www.stl-tsl.org/en/media/press-releases/1700trial-chamber-dismisses-motions-to-reconsider-in-absentia-proceedings. Acesso em: 28 fev. 2019. TORTORA, Giorgia. The Special Tribunal for Lebanon and the discussion of residual mechanisms. Proceedings of the Annual Meeting (American Society of International Law), Cambridge, v. 104, p. 45-47, Mar. 2010.

TRINDADE, Antônio Augusto Cançado. Os tribunais internacionais contemporâneos. Brasília: FUNAG, 2013. Disponível em: http://funag.gov.br/biblioteca/download/1018-tribunaisinternacionais-contemporaneos.pdf.

UNITED NATIONS. Security Council. Resolution 1.595, 7 Apr. 2005a. Disponível em: https:// undocs.org/S/RES/1595(2005).

UNITED NATIONS. Security Council. Resolution 1.644, 15 Dec. 2005b. Disponível em: https:// undocs.org/S/RES/1644(2005).

UNITED NATIONS. Security Council. Resolution 1.664, 29 Mar. 2006. Disponível em: https:// undocs.org/S/RES/1664(2006).

UNITED NATIONS. Security Council. Resolution 1.757, 30 May 2007. Disponível em: https:// undocs.org/S/RES/1757(2007).

WORLDOMETERS. Lebanon Population. Disponível em: http://www.worldometers.info/worldpopulation/lebanon-population. Acesso em: 28 fev. 2019. 
